\title{
ENSAIO ACADÊMICO SOBRE A FORMAÇÃO DE PROFESSORES PARA EDUCAÇÃO PROFISSIONAL E TECNOLÓGICA NO BRASIL: DESAFIOS E PERSPECTIVAS
}

\author{
Fabiana Elayne Barros Damasceno ${ }^{1}$ \\ Thiago Coelho Silveira ${ }^{2}$ \\ Keylla Cristina Coelho Lima ${ }^{3}$ \\ Ivesmary Loureiro Ribeiro Magalhães ${ }^{4}$ \\ Wender Roberto Barros de Oliveira ${ }^{5}$ \\ Soliana Carolina Sodré Nicacio ${ }^{6}$
}

RESUMO: O presente ensaio tem por objetivo levar a reflexão sobre a formação de professores para educação profissional e tecnológica, com o propósito de analisar as políticas de formação de professores para EPT, além de mapear e compreender a produção de conhecimento a respeito do assunto e evidenciar desafios e perspectivas para a formação de professores que atuam na Educação Profissional e Tecnológica no Brasil(EPT), apresentando para isso uma análise sobre como ocorre a formação de professores para atender as demandas desta modalidade de ensino, partindo de uma contextualização histórica e política de formação de docentes para EPT no Brasil. A metodologia empregada pautou-se em uma pesquisa de abordagem qualitativa e para tanto, utilizou-se da pesquisa bibliográfica, a partir de obras de autores que examinam acerca da formação docente para atuar na EPT. Este ensaio acadêmico apresenta a seguinte estrutura: a) contextualização histórica e política da formação docente para EPT no Brasil; b) desafios e as perspectivas da formação de professores para a EPT no Brasil; c) considerações finais. Salienta-se, ainda que, a reflexão refere-se a um estudo específico e limitado que pode contribuir para o fomento das discussões a respeito do tema em questão.

Palavras-chave: Educação profissional. Formação de professores. Desafios na formação docente.

\footnotetext{
${ }^{1}$ Mestranda do mestrado profissional PROFEPT-IFMA, Especialista em Engenharia Ambiental, em Docência do Ensino Superior e em Mediação de Conflitos e Arbitragem pela faculdade Unyleya. Graduada em Geografia Licenciatura pela Universidade Estadual do Maranhão (2010), em Geografia Bacharel pela Universidade Federal do Maranhão (UFMA) e em Direito pela FACEM- Faculdade do estado do Maranhão.

${ }^{2}$ Doutor em História (UNISINOS). Professor do Instituto Federal do Maranhão (IFMA, Campus Presidente Dutra e do Programa de Pós-graduação em Educação Profissional e Tecnológica (ProfEPT/IFMA).

${ }^{3}$ Mestranda do mestrado profissional PROFEPT-IFMA, possui graduação em Letras e especialista na área de língua espanhola.

${ }^{4}$ Mestranda do mestrado profissional PROFEPT-IFMA, possui graduação em Tecnologia em Eletrônica Industrial e em Licenciatura em Pedagogia e especialização em Gestão Escolar;

${ }^{5}$ Especialista em engenharia de produção, especialista em logística empresarial e especialisat em projetos. Bacharel em administração e teologia.

${ }^{6}$ Especialista em gestão pública e graduada em turismo.
} 
ABSTRACT: This essay aims to reflect on teacher training for professional and technological education, with the aim of analyzing teacher training policies for EPT, in addition to mapping and understanding the production of knowledge on the subject and highlighting challenges and perspectives for the formation of teachers who work in Professional and Technological Education in Brazil (EPT), presenting for this an analysis on how the formation of teachers occurs to meet the demands of this type of teaching, starting from a historical contextualization and training policy of teachers for EPT in Brazil. The methodology used was based on a research with a qualitative approach and, for that, bibliographical research was used, based on works by authors who examine about teacher training to work in the EPT. This academic essay presents the following structure: a) historical and political contextualization of teacher education for EPT in Brazil; b) challenges and perspectives for teacher training for EPT in Brazil; c) final considerations. It is noteworthy that the reflection refers to a specific and limited study that can contribute to the promotion of discussions on the topic in question.

Keywords: Professional education. Teacher training. Challenges in teacher training.

\section{INTRODUÇÃO}

O presente ensaio acadêmico trata-se de uma reflexão com o propósito de analisar as Políticas de Formação de Professores, a fim de mapear e compreender a produção de conhecimento a respeito do assunto e evidenciar desafios e perspectivas para a formação de professores que atuam na Educação Profissional e Tecnológica no Brasil(EPT),

apresentando para isso uma análise sobre como ocorre a formação de professores para atender as demandas desta modalidade de ensino. Salienta-se que a reflexão refere-se a um estudo específico e limitado que pode contribuir para o fomento das discussões a respeito do tema em questão.

Nesta direção, este ensaio analisa a formação de professores no cenário brasileiro e na modalidade da Educação Profissional e Tecnológica(EPT), tomando como referência uma concepção de EPT que supere a dualidade existente, decorrente de aspectos históricos e culturais. Esta dualidade é percebida em duas posições, nem sempre compatíveis, onde de um lado, espera-se que a EPT esteja voltada para trabalhar com a formação humana e técnica dos estudantes e ou trabalhadores, para que eles possam, na escola, se conscientizar que por meio do seu trabalho, eles garantirão a sua subsistência e de outro lado, a EPT está atendendo interesses socioeconômicos, qualificando pessoas para o mercado de trabalho e com ele os serviços necessários aos seus interesses. Diante disto, muitos professores que atuam na EPT, principalmente a que ministra os componentes curriculares técnicos, não tem uma formação específica para a docência, visto que a legislação (BRASIL, 20I2a) 
permite o exercício da docência na EPT por profissionais sem formação pedagógica. Então, bacharéis e tecnólogos estão aptos a conduzir a formação profissional dos estudantes, muitas vezes sem o aprofundamento pedagógico e não conseguem articular conhecimentos escolares com conhecimentos sociais, tecnológicos e do trabalho por meio de metodologias adequadas.

Apesar de os saberes docentes ocorrerem pela prática docente e pelas vivências e experiências de vida, a formação pedagógica deveria ser considerada um pré-requisito para o exercício da docência para a EPT. Segundo Saviani (1996), os saberes pedagógicos são os conhecimentos produzidos pelas ciências da educação e sintetizados nas teorias educacionais.

Esses saberes têm a finalidade de atrelar as bases educacionais com as orientações no trabalho, definindo a identidade do educador como um profissional da educação e o diferenciando daqueles que apenas "ministram aulas".

Uma proposta de formação docente específica para a EPT nunca se constituiu em políticas públicas de Estado, embora já tenham havido discussões em âmbito político sobre o assunto. A formação configurando-se em programas emergenciais, especiais, aligeirados e despolitizados. E esta realidade de recrutar profissionais do mercado de trabalho para a docência na EPT, é uma tendência que persiste até os dias atuais. No entanto, os Institutos Federais de Educação, Ciência e Tecnologia (IF) representam um grande avanço para a condução da proposta de formação profissional humana, transformadora e emancipatória para EPT, onde existem professores que são incentivados a realizarem constantemente formação continuada e pedagógica.

Seria essencial para conquistas e evoluções no âmbito da EPT, a implantação de um processo de incentivo aos professores que não possuem formação pedagógica. Nessa perspectiva, a formação de professores para a EPT é decisiva para que a atual política de expansão, interiorização e democratização dessa modalidade educacional se efetive com qualidade e é claro, valorizando o docente

Entende-se que a EPT não se deve voltar apenas para as demandas do mercado de trabalho, mas estar focada na formação profissional de forma integral, contemplando todas as dimensões humanas e tornando os alunos, profissionais para a vida na sociedade e para o mundo do trabalho. No entanto, o atual cenário histórico apresenta desafios para a formação inicial e continuada desses docentes em função da expansão da oferta da EPT, 

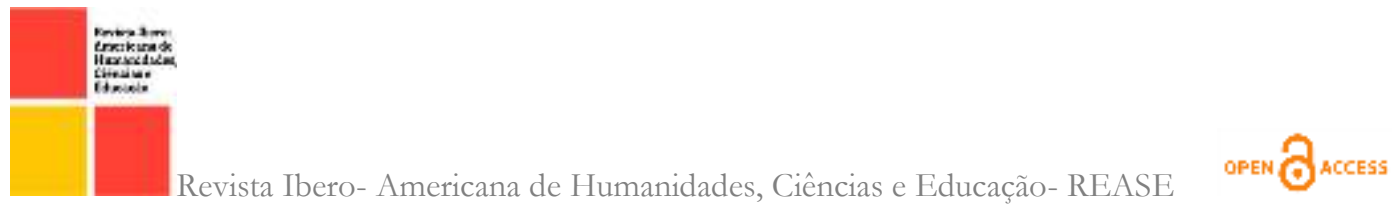

das especificidades desta modalidade e das exigências que estas impõem ao professor porque nela se insere sem uma base pedagógica que oriente as suas práticas.

Desse modo, pretende-se refletir sobre os desafios e as perspectivas para formação de professores para EPT, partindo de uma contextualização histórica e política de formação de docentes para EPT no Brasil. A metodologia empregada pautou-se em uma pesquisa de abordagem qualitativa e para tanto, utilizou-se da técnica bibliográfica narrativa, a partir de obras de autores que examinam acerca da formação docente para atuar na EPT. Este ensaio acadêmico apresenta uma estrutura que pode ser assim descrita: a) trata de uma breve contextualização histórica e política da formação docente para EPT no Brasil; b) reflete sobre os desafios e as perspectivas da formação de professores para a EPT; c) apresenta as considerações finais.

\section{CONTEXTUALIZAÇÃO HISTÓRICA E POLÍTICA DA FORMAÇÃO DOCENTE PARA EPT NO BRASIL}

É sabido que a formação de professores no Brasil iniciou com a fundação das Escolas Normais no final do século XIX, em que essas Escolas Normais referiam-se ao ensino secundário que logo após o século XX denomina-se de nível médio, para formar professores primários atribuindo-se ao nível superior a tarefa de formar os professores secundários.

Com a promulgação da Lei no 9.394 de 20 de dezembro de 1996, esta formação passa a ser realizada (e exigida) em nível de ensino superior, conforme pode ser conferido no seu Art. 62 onde estabelece que os professores que atuam nos diversos níveis da educação básica devem ter formação em nível superior, em cursos de licenciatura.

Art. 62. A formação de docentes para atuar na educação básica far-se-á em nível superior, em curso de licenciatura plena, admitida, como formação mínima para o exercício do magistério na educação infantil e nos cinco primeiros anos do ensino fundamental, e oferecida em nível médio, na modalidade normal (BRASIL, I996, p. 30).

Segundo Saviani (2003), é possível identificar momentos da formação de professores no Brasil em períodos. As escolas normais ofereciam somente a formação específica. Cabia ao professor preocupar-se principalmente com os conteúdos já estabelecidos pelos currículos das escolas de Primeiras Letras, em que os professores eram instruídos no método do ensino mútuo, às próprias custas com preocupação para a preparação didática. Desta maneira, a questão didático-pedagógica não entrava neste cenário. 
Saviani (2003) retrata ainda, o padrão que resultou da aplicação do Decreto-Lei no I.190/39 que ficou conhecido em todo o país como o "esquema $3+\mathrm{I}$ "( três anos de "formação específica" e um ano de "curso de Didática"), empregados na estruturação e organização dos cursos de licenciatura e de Pedagogia. Desta maneira, os primeiros tinham a incumbência de formar os professores para ministrar aulas de diversos componentes curriculares nas escolas secundários e os segundos, formavam professores para atuarem nas Escolas Normais, justificando assim o esquema, ou seja, três anos dedicados ao estudo dos componentes curriculares específicos e um para a formação didática, incorporando, um modelo baseado nos conteúdos culturais cognitivos. Esse decreto tinha a função de formar bacharéis e licenciados para as diversas áreas do conhecimento, instituindo-se o padrão federal, adaptando os currículos básicos oferecidos pelas instituições do país. Tal decreto define, para a formação de bacharéis, a duração de três anos, após os quais, adicionando-se um ano de Didática, formando, desta forma, os licenciados.

A preocupação com a formação de professores intensificou-se a partir do século XIX, onde as Universidades já discutiam a necessidade desta formação para os docentes. Assim, o processo de formação de professores ocorria durante o percurso no processo de aprendizagem, predominando o "aprender fazendo",como ocorria nas instituições de ofício. Entretanto, a formação de professores surge com projetos voltados para a organização e sistematização para oferecimento nacional do ensino. Esses projetos assumiram a função de organizar diversas escolas em um mesmo padrão, o que gerou um grande dilema quanto aos aspectos da formação de professores.

Para enfrentamento deste contexto, foram criadas as Escolas Normais, que segundo Taruni (2000, p.72)passaram a oferecer um curso híbrido, que oferecia, ao lado de um exíguo currículo profissional, um ensino de humanidades e ciências quantitativamente mais significativo, estabelecendo o nível médio para a formação de professores primários e ao nível superior a formação para o ensino secundário.

Diante disso, surgem dois modelos de formação de professores, que segundos Saviani são: a) modelo dos conteúdos culturais-cognitivos, onde a formação do professor se esgota na cultura geral e no domínio específico dos conteúdos da área de conhecimento correspondente à disciplina que lecionará e outro b) modelo pedagógico-didático: contrapondo-se ao anterior, este modelo considera que a formação do professor propriamente dita só se completa com o efetivo preparo pedagógico-didático. $\mathrm{Na}$ história 

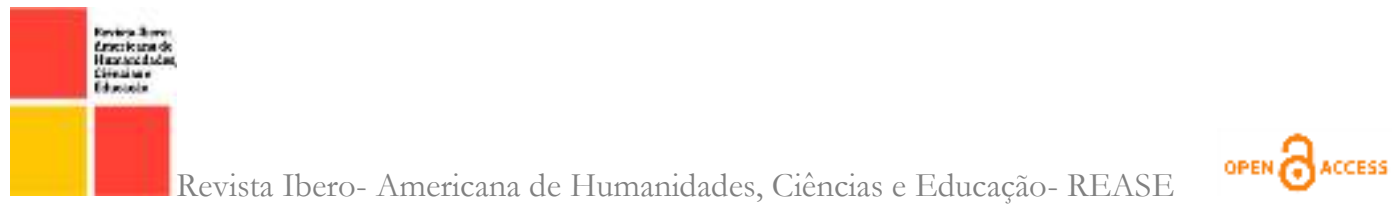

da formação de professores constatamos que o primeiro modelo predominou nas universidades e demais instituições de ensino superior que se encarregaram da formação dos professores secundários, ao passo que o segundo tendeu a prevalecer nas Escolas Normais, ou seja, na formação dos professores primários.

Esses modelos são importantes, pois devem fazer parte do processo de formação de professores de forma articulada, realizada de maneira crítica e reflexiva. A preocupação com a estruturação e organização deste "novo" modelo que representa a ligação entre os dois modelos citados anteriormente, explícita os desafios da formação de professores em especial para EPT.

Saviani em seu texto "A formação de professores: aspectos históricos e teóricos do problema no contexto brasileiro" afirma que, com relação aos dois modelos acima citados existem um dilema que se expressa do seguinte modo: admite-se os dois aspectos, os conteúdos de conhecimento e os procedimentos didático-pedagógicos, e os dois devem integrar o processo de formação de professores, porém, como articulá-los adequadamente? A ênfase nos conhecimentos que constituem a matéria dos currículos escolares leva a dar precedência ao modelo dos conteúdos culturais cognitivos. Nesse caso, na organização institucional, seríamos levados a situar a questão da formação de professores no âmbito dos institutos ou faculdades específicos. Inversamente, se nosso ponto de partida for o modelo pedagógico-didático, tenderemos a situar os cursos no âmbito das faculdades de educação.

Assim, para tentar superar este dilema foram criados os cursos de licenciaturas que buscam formar professores por área de conhecimento não apenas sob o aspecto do domínio de conteúdos mas sobretudo um professor mais humano que forme seres humanos conscientes e autônomos para o trabalho e para a vida em sociedade.

Sabe-se que a formação docente deixa muitas questões abertas sobre que processos e práticas seriam mais efetivos no contexto da Educação Brasileira, tendo em vista que muitas políticas deveriam ser formuladas e os de investimentos seriam maiores do que aqueles relacionados com as condições que os professores enfrentam hoje em dia, tais como, cargas horárias exaustivas, salários, baixos, condições precárias de trabalho, entre outras.

Segundo Brzezinski e Garrido (2002), a formação de professores oferecida urge por mudanças na direção de tornar o professor um profissional conectado nesta conjuntura, ou 
seja, uma formação onde as competências desenvolvidas estejam correlacionadas às demandas e a esta realidade social, cultural e política. Elas afirmam ainda que, a formação pedagógica do licenciado não consegue por si dar conta da problemática deste novo contexto e, por isso, é necessário e fundamental entender e identificar quais as razões das resistências de estagiários e professores no que se refere à mudança de práticas educativas.

Nesse sentido, as políticas educacionais evidenciadas atualmente se remetem em atender apenas as demandas ditadas pelo mercado de trabalho, segundo Evangelista, Moraes e Pacheco (200I). Elas afirmam ainda que, as preocupações referentes à qualificação docente necessita superar as competências demandadas pelo mercado, algo que já começa a se constituir neste processo. Desta forma, a formação de professores necessita ser repensada do ponto de vista do campo educacional e de acordo com as demandas e realidades do contexto situacional que se encontra, pois a questão acerca do processo da prática educativa perpassa questões meramente de interesse político e a formação do professor deve ser vista como um processo contínuo que se constituí nas práticas em sala de aula. Diante disso, revisitar a história das políticas de formação docente para a EPT possibilita reconhecer que elas são determinadas por programas efêmeros e imediatistas, com o intuito de suprir a falta de professores qualificados, licenciados ou egressos de cursos de formação especial para professores, para exercer a docência no ensino técnico.

Sabe-se que os saberes pedagógicos contribuem para a prática docente desde que sejam vistos sob a perspectiva da unidade teoria e prática aspirando a interdependência entre ambos, portanto, a ação do professor e a prática diária em sala de aula constituem elementos relevantes para a implementação e efetivação de saberes no campo prático e teórico, desde que sejam apropriados com criticidade e reflexão constante.

Essa reflexão é fundamental para o processo de formação de professores e reforça a tese de que a ação reflexiva está imbricada na formação do professor que pesquisa e que prima por sua autonomia profissional. Entretanto, não há autonomia intelectual sem uma formação consolidada e firme (TIBALLI, 200I).

Alarcão (2013) afirma que, uma atitude prática reflexiva traduz-se numa reflexão na ação e numa reflexão sobre a ação e por este motivo, os professores reflexivos podem desempenhar seu papel com maior autonomia, ao se fazer perguntas, ao compreenderem seus fracassos, ao projetarem o seu futuro, ao serem mais flexíveis e ao buscar o como e o 

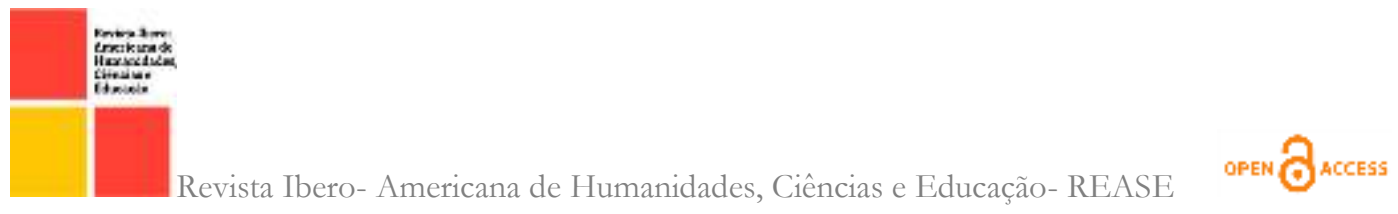

porquê das coisas, por meio da criticidade, contribuindo, desta forma, para a formação crítica reflexiva dos seus alunos.

O processo de formação de professores no Brasil tem necessariamente que estabelecer por meta a formação de profissionais que reflitam sobre o seu fazer, que sejam capazes de confrontá-lo com os saberes teóricos, construídos na academia e que construam fazeres, a partir desses confrontos, para que dessa forma possam enfrentar os desafios que surjam no cotidiano do seu exercício profissional.

Desta forma, o professor precisa de uma formação sólida, que proporcione não apenas o domínio dos conhecimentos específicos de sua área, mas também dos conhecimentos pedagógicos, para que haja uma integração entre o conhecimento geral e o específico e fortaleça, principalmente na EPT, as relações entre cultura, trabalho, ciência e tecnologia, o que torna necessário que as instituições formadoras de professores se organizem para atender as novas demandas educacionais, principalmente com relação a formação de professores para EPT, que estão diretamente ligadas ao mundo do trabalho.

Diante disso, Kuenzer afirma que o professor deve ser: [...] capaz de, apoiando-se nas ciências humanas, sociais e econômicas, compreender as mudanças ocorridas no mundo do trabalho, construindo categorias de análise que lhe permitam apreender as dimensões pedagógicas presentes nas relações sociais e produtivas, de modo a identificar as novas demandas de educação e a que interesses elas se vinculam. Ou seja, compreender historicamente os processos de formação humana em suas articulações com a vida social e produtiva, as teorias e os processos pedagógicos, de modo a ser capaz de produzir conhecimento em educação e intervir de modo competente nos processos pedagógicos amplos e específicos, institucionais e não institucionais, com base em uma determinada concepção de sociedade (KUENZER, 1999, p. 170).

Todos esses fatores quando somados indicam a importância da questão da formação de professores de educação básica frente aos desafios impostos pelas constantes transformações políticas, econômicas e sociais nas sociedades contemporâneas. Desta forma, formar bons profissionais na área da educação implica repensar aspectos relacionados não apenas aos cursos de formação inicial (licenciaturas), como também aspectos relativos à formação continuada, reuniões de trabalho pedagógico, prática em sala de aula, assim como as condições gerais de trabalho nas escolas e também planos de carreira e salários. Nessa concepção, é que o professor da EPT precisa estar consciente de 
que seu ofício não é somente conteudista. E para isso, uma formação para a docência inicial ou continuada é essencial. Para tanto, a próxima seção discutirá os desafios e as perspectivas no cenário da formação de professores para a EPT no Brasil.

\section{Desafios e perspectivas para a formação de professores para a educação profissional e tecnológica no Brasil}

Evidencia-se atualmente na educação profissional e tecnológica brasileira a necessidade de uma formação de docentes que articule teoria e prática, o científico e o tecnológico, com conhecimentos que permitam aos professores aperfeiçoar a atuação no mundo do trabalho de forma autônoma e com espírito crítico e criativo, pois, ensinar hoje, exige desenvolvimento de habilidades de comunicação, raciocínio, criticidade e criatividade, que não fiquem apenas nas intenções, mas que sejam calcadas no desenvolvimento contínuo e isso passa, pela atualização dos saberes. (GIESTA, 200I, p. $412)$.

Machado (2008, p. 15) afirma o seguinte, sobre a formação de professores adequada à atual complexidade do mundo do trabalho:

\footnotetext{
Os professores de educação profissional enfrentam novos desafios relacionados às mudanças organizacionais que afetam as relações profissionais, aos efeitos das inovações tecnológicas sobre as atividades de trabalho e culturas profissionais, ao novo papel que os sistemas simbólicos desempenham na estruturação do mundo do trabalho, ao aumento das exigências de qualidade na produção e nos serviços, à exigência de maior atenção à justiça social, às questões éticas e de sustentabilidade ambiental. São novas demandas à construção e reconstrução dos saberes e conhecimentos fundamentais à análise, reflexão e intervenções críticas e criativas na atividade de trabalho.
}

O docente ao se sentir confiante e apto a compreender e analisar as políticas, procedimentos, resultados, estudos, propostas educacionais inerentes à sua profissão e qualificação faz alavancar sua identidade profissional e com isso ele se compromete com sua formação inicial e continuada. Esta formação enquanto um processo reflexivo facilita a introdução de novos objetivos de ensino e aprendizagem, novas metodologias de ensino e de novas construções de saberes e sentidos que auxiliam na organização do cotidiano escolar.

A formação de professores para EPT, não deve se reduzir à aprendizagem de técnicas que os preparem para tarefas específicas e pontuais, mas de buscar superar esse fazer. O espaço da formação serve como qualificação profissional e encontro de discussões pedagógicas deve redefinir conceitos no interior da formação docente. 
Tardif (2008, p. 52) expressa:

É através das relações com os pares e, portanto, através do confronto entre os saberes produzidos pela experiência coletiva dos professores que os saberes experienciais adquirem uma certa objetividade: as certezas subjetivas devem ser então sistematizadas a fim de se transformarem num discurso de experiência capaz de informar ou de formar outros docentes e de fornecer uma resposta a seus problemas.

Apesar de todas essas considerações, pode-se reconhecer que a história dos programas e das políticas de formação de professores para a EPT são determinadas por programas efêmeros e imediatistas, com o intuito de suprir a falta de professores qualificados, licenciados ou egressos de cursos de formação especial para professores, para exercer a docência no ensino técnico. A trajetória da formação de docentes para a EPT no Brasil, foi sempre marcado por cursos de formação de professores adjetivados, utilizando terminologias como 'apropriado', 'especial' e 'emergencial'. Sempre existiram portarias, decretos, resoluções, pareceres e programas de governo, que oficializam e facilitam o acesso de profissionais, não professores, às salas de aula da EPT, sendo que estas ações não se constituem em políticas públicas de Estado. Para o Estado não era interessante, aplicação de recursos orçamentários mais elevados para a formação dos profissionais docentes em EPT, tendo em vista que buscava-se satisfazer uma lógica mercadológica, uma demanda de formação de mão de obra para o mercado de trabalho.

Atualmente, $\mathrm{O}$ paradigma tecnológico impõe novos desafios à formação dos professores da EPT, pois não basta mais só ter competência tecnológica, domínio de conteúdo e titulação compatível com a função ou ser um profissional de renome no mercado de trabalho para legitimar-se como professor. Essa concepção de que para ser professor da Educação Profissional e Tecnológica(EPT), tem que ter competência técnica, domínio de conteúdo, titulação, formação em pesquisa e publicações científicas ou ser profissional de renome no mercado vem sendo questionada, visto que a força de trabalho requerida pela dinâmica científica e tecnológica mundialmente disseminada precisa-se de um perfil de docente capaz de desenvolver pedagogias do trabalho independente e criativo, construir a autonomia progressiva dos alunos e participar de projetos interdisciplinares, segundo Machado(2008, p. 16).

Para formação dos futuros professores será necessário a adaptação dos currículos das licenciaturas, com a finalidade de uma formação de docentes pesquisadores, capazes de atuar no enfrentamento da realidade escolar, por meio de uma atuação didático- 
metodológica condizente com as demandas do processo de ensino e aprendizagem da EPT (SANTOS, 2017). Neste sentido, pretende-se estabelecer a formação de um trabalhador que tenha consciência de seu papel político, econômico e social e que, portanto, não seja alienado aos sistemas produtivos.

Como observa-se, várias são as questões inerentes aos desafios atuais da formação de professores para a EPT no Brasil. Além disso, esses desafios manifestam-se de vários modos, principalmente quando se pensa nas novas necessidades e demandas políticopedagógicas dirigidas a eles: mais diálogos com o mundo do trabalho e a educação geral; práticas pedagógicas interdisciplinares e interculturais; enlaces fortes e fecundos entre tecnologia, ciência e cultura; processos de contextualização abrangentes; compreensão radical do que representa tomar o trabalho como princípio educativo; perspectiva de emancipação do educando, porquanto sujeito de direitos e da palavra.

Atualmente, as exigências relativas ao perfil para a docência na EPT estão mais elevadas, considerando-se que o professor dessa modalidade:

[...] não pode moldar-se à feição de transmissor de conteúdos definidos por especialistas externos, mas compor-se por características em que seu papel de professor se combine com as posturas de: a) Intelectual; b) Problematizador; c) Mediador do processo ensino-aprendizagem; d) Promotor do exercício de liderança intelectual; e) Orientador sobre o compromisso social que a ideia de cidadania plena contém; f) Orientador sobre o comportamento técnico dentro de sua área de conhecimento (ARAÚJO, 2008, p. 59).

Assim, ao professor não basta conhecer, mas saber integrar no ensino as dimensões da formação geral e técnica. É necessário concepções teórico-práticas que possibilitem migrar de um modelo convencional de ensino e problematizar o mesmo na EPT (CASTAMAN; RODRIGUES, 2020). Por isso, o trabalho desse docente deve partir de uma formação que permita aos estudantes o desenvolvimento da criatividade, do pensamento crítico, do trabalho intelectual. Sua formação deve ser crítica, reflexiva e dotada de responsabilidade social (MOURA, 2008).

Diante destas considerações sobre os desafios da formação de professores para a EPT, entende-se que uma das perspectivas de formação seja o Programa de Pós-Graduação em Educação Profissional e Tecnológica (ProfEPT) - Curso de Mestrado em Educação Profissional e Tecnológica oferecido em rede nacional. O ProfEPT tem por propósito formar profissionais capazes de elaborar e desenvolver pesquisas aplicadas ligadas ao ensino, de espaços formais e não formais na EPT. Assim, por está dentro de uma proposta 
de política educacional, que tem em seu âmago a formação específica para esta modalidade, o PROFEPT traz uma nova forma de pensar a educação profissional e tecnológica.

Além do ProfEPT, destacam-se outros programas específicos de formação de professores já reconhecidos pelo MEC, como por exemplo o PARFOR Programa de Formação Inicial e Continuada, de Professores para a Educação Básica, Presencial e à Distância e o Programa Institucional de Bolsa de Iniciação à Docência (PIBID). Cita-se também, aqueles inerentes à EPT, como o Projeto Gestor - Programa de Pós-graduação em Educação Tecnológica e formação de mestres para a Rede Federal de Educação Profissional, Científica e Tecnológica; também existe o Programa de Pós-Graduação em Educação Agrícola (PPGEA), o Programa Institucional de Qualificação Docente para a Rede Federal de Educação Profissional, Científica e Tecnológica (PIQDTEC) e o Programa Educação em Agroecologia e Sistemas Orgânicos de Produção.

Além dessas perspectivas aponta-se a necessidade de: promover a identidade profissional dos professores por meio de políticas de formação, valorização e carreira docente; desenvolver formação inicial e continuada que contribua para dar o sentido de pertencimento aos professores e que dialogue com as expectativas, realidades e desafios do trabalho da docência neste campo educacional; estimular o conhecimento por parte dos professores dos determinantes internos e externos à sua atuação profissional, das condições da sua materialidade, das crenças e valores em disputa, dos diferentes saberes que precisam convocar, das especificidades da profissão, das necessidades do desenvolvimento profissional e de como fomentá-lo.

Por fim, é importante que a formação contínua dos docentes aconteça e que os espaços de formação de professores como as licenciaturas considerem a modalidade EPT, as políticas públicas consistentes que atendam a conjuntura contextual da EPT e os seus fundamentos na produção de saberes e fazeres comprometidos com uma formação humana integral, visto que o processo de formação de professores da EPT, só será considerado significativo quando: Romper com a forma conservadora de ensinar, aprender, pesquisar e avaliar; Reconfigurar saberes e superar as dicotomias existentes entre os conhecimentos teóricos e práticos; Permitir exercitar novas alternativas teórico-metodológicas; Desenvolver habilidades para lidar com novas tecnologias, compreendendo as metodologias e as práticas que circulam no universo educacional; Promover a necessidade de conviver e trabalhar de forma interdisciplinar: capacidade de adaptação às diferentes 
realidades. Saber trabalhar de forma independente e em equipe; Incentivar o domínio de conteúdos e das linguagens das áreas de atuação; Estimular o professor a ser pesquisador, permitindo saber diferenciar informação de conhecimento, ter capacidade de análise, reflexão e possuir hábito de leitura; Esses princípios revelam que formar professores para a EPT acarreta analisar a docência com profundidade. Para isso tornam-se necessárias atividades formativas e reflexivas capazes de compreender criticamente questões cotidianas inerentes à profissão docente, prática esta que implica nas ideias de formação, reflexão e crítica.

\section{CONSIDERAÇÕES FINAIS}

Diante do estudo realizado para a elaboração do presente ensaio, conclui-se que a formação de professores vem se revestindo de importância cada vez maior, sendo percebida como um processo ensino-aprendizagem de reflexão essencial para a construção da educação de qualidade. Para que um processo de formação de docentes da EPT seja considerado relevante é necessário que os professores desenvolvam a capacidade de compreender sua prática pedagógica embasada teoricamente, possibilitando desta forma a análise crítica contínua a respeito das questões do mundo do trabalho, da instituição de ensino e do seu papel como sujeito neste processo. A formação não pode ser resumida a encontros ou palestras; é necessário construir um processo colaborativo, buscando o desvelamento das condições sociais que perpassam a prática pedagógica.

Sendo assim, precisa ser um processo contínuo, integrado ao dia a dia do professor e da escola. Diante dessas circunstâncias, a prática desenvolvida no processo de formação de professores da EPT deve possibilitar não só o contato com a realidade e a aquisição de habilidades, mas também refletir criticamente sobre as práticas desenvolvidas, em articulação com as concepções teóricas, discutidas em atividades de formação de professores.

Cabe destacar que a formação de professores da EPT deve ser realizada num contexto dinâmico, no qual o sujeito deve ser desafiado a ser autônomo e independente, desenvolvendo um trabalho coletivo competente. $\mathrm{Na}$ instituição de ensino é recomendável que o processo de formação seja desenvolvido envolvendo todos os profissionais, possibilitando a execução na prática daquilo que foi refletido e analisado teoricamente. Assim, analisar o contexto em que está inserida a formação de professores para a EPT, assim como os desafios históricos e as perspectivas contemporâneas deste processo, é 

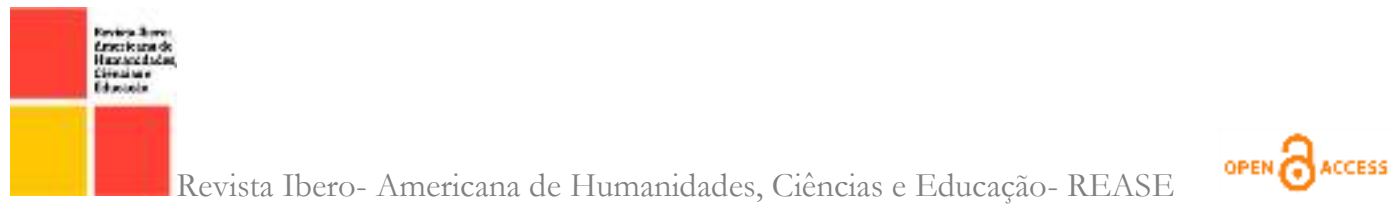

primordial e leva-nos a refletir sobre o quanto é importante a formação dos professores, pois, antes de tudo, a docência é uma profissão de relações humanas e a qualidade da educação, perpassa, pela formação de seus profissionais.

Além disso, essa formação deve se dar por meio de uma política adotada pelo poder público e assumida pelos profissionais diretamente envolvidos com essa modalidade. Portanto, uma política definida para a formação de professores que atenda a tais necessidades será certamente um grande estímulo para a superação da atual debilidade teórica e prática deste campo educacional com relação aos aspectos pedagógicos e didáticos. É sabido que o docente da EPT deve ser um sujeito reflexivo e preparado para a pesquisa, aberto ao trabalho coletivo e à ação crítica e cooperativa, comprometido com sua atualização permanente na área de formação específica e pedagógica. Sabe-se que a docência nessa modalidade precisa ser reconhecida, evidenciando o ensino de acordo com a sistematização do saber de sua área. Além disso, é necessário superar a carência de políticas de formação fragmentadas e emergenciais.

Diante disso, o ensaio nos leva a perceber que a reflexão que acontece no processo de formação de professores da EPT promove o desenvolvimento de conhecimentos que se integram no contexto escolar, oportunizando a construção de novos saberes e competências essenciais para o desenvolvimento da prática docente. Pode-se afirmar que nenhum professor consegue "ser professor" e "fazer aulas" se não se atualizar constantemente. Portanto, é preciso que o professor se mantenha permanentemente motivado e incentivado pela instituição de ensino e pelo poder público, numa dinâmica onde todos os servidores devem atuar de forma integrada, já que a educação não acontece de forma isolada. E por fim, diante das considerações proferidas sobre a conjuntura histórica da EPT e dada a importância do tema, espera-se que o presente trabalho, por suas limitações, estimule novas investigações, dando continuidade ao presente estudo, o que pode incluir produções sobre o processo de formação de professores em outros períodos históricos da educação brasileira, abordando aspectos relacionados à construção da profissionalização e identidade docente.

\section{REFERÊNCIAS}

ALARCÃO, I. O papel do supervisor no desenvolvimento do professor reflexivo.In: . (Org). Formação reflexiva de professores. Estratégias de Supervisão.6. ed. Porto: Porto, 2013. p. 89-II9. 
ARAÚJO, R. M. de L. Formação de docentes para a educação profissional e tecnológica: por uma pedagogia integradora da educação profissional.Trabalho e Educação, Campinas, v.I7, n. 2, p. 53-63, maio/ago. 2008. Disponível em: https://periodicos.ufmg.br/index.php/trabedu/article/view/8586. Acesso em: Io jan. 202I.

BRASIL. Lei de Diretrizes e Bases da Educação Nacional. Brasília(DF): Imprensa Nacional, 1996. Disponível em: http://www.planalto.gov.br/ccivil_03/Leis/L9394.htm. Acesso em: 09 abr. 2021.

BRASIL. Lei № 12.772, de 28 de dezembro de 2012. Dispõe sobre a estruturação do Plano de Carreiras e Cargos de Magistério Federal; sobre a Carreira do Magistério Superior, de que trata a Lei no 7.596, de io de abril de 1987; sobre o Plano de Carreira e Cargos de Magistério do Ensino Básico, Técnico e Tecnológico e sobre o Plano de Carreiras de Magistério do Ensino Básico Federal, de que trata a Lei no 11.784 , de 22 de setembro de 2008; sobre a contratação de professores substitutos, visitantes e estrangeiros, de que trata a Lei no 8.745 de 9 de dezembro de 1993; sobre a remuneração das Carreiras e Planos Especiais do Instituto Nacional de Estudos e Pesquisas Educacionais Anísio Teixeira e do Fundo Nacional de Desenvolvimento da Educação, de que trata a Lei no 11.357 , de 19 de outubro de 2006; altera remuneração do Plano de Cargos Técnico-Administrativos em Educação; altera as Leis $\mathrm{n}$ - 8.745, de 9 de dezembro de 1993, II.784, de 22 de setembro de 2008, II.091, de I2 de janeiro de 2005, II.892, de 29 de dezembro de 2008, II.357, de I9 de outubro de 2006, II.344, de 8 de setembro de 2006, 12.702, de 7 de agosto de 2012, e 8.168, de i6 de janeiro de I991; revoga o art. $4^{\circ}$ da Lei $\mathrm{n}^{\mathrm{O}}$ 12.677, de 25 de junho de 2012; e dá outras providências. 2012 a. Disponível em: http://www.planalto.gov.br/ ccivil_03/_ato2orI2014/2012/lei/li2772.htm. Acesso em: 24 nov. 2021.

BRZEZINSKI, I.; GARRIDO, E. O que revelam os trabalhos apresentados no GT Formação de Professores da ANPED. Série Estado do Conhecimento. INEP, v. I, n. 6, p. 303-328, 2002.

EVANGELISTA, O.; MORAES, M. C. M.; PACHECO, J. A. P. Políticas educacionais nos anos 90: a formação de professores no Brasil e em Portugal. Educar em Revista, Curitiba, n. I8, p. 185-200, 2001.

CASTAMAN, A. S.; RODRIGUES, R. A. Formando formadores: programa de pósgraduação em rede na área de ensino. Revista Brasileira da Educação Profissional e Tecnológica, Natal, v.I, n. i8, p. e8520, fev. 2020. Disponível em: http://www2.ifrn.edu.br/ojs/index.php/RBEPT/article/view/8520. Acesso em: i9 jan. 202I.

GIESTA, Nágila C. Cotidiano escolar e formação reflexiva do professor: moda ou valorização do saber docente?Araraquara: JM, 2001.

KUENZER, A. Z. As políticas de formação: a constituição da identidade do professor sobrante. Educação e Sociedade[online]. 1999, vol. 20, n. 68, p. 163-183. Disponível em: http://www.scielo.br/pdf/es/v2on68/aogv2068.pdf. Acesso em: 20 jan. 202I 
MACHADO, Lucília Regina de Souza. Diferenciais inovadores na formação de professores para a educação profissional. Revista Brasileira da Educação Profissional e Tecnológica. Brasília: MEC/Setec, v. I, n. I, 2008, p. 8-22.

MOURA, D. H. A formação de docentes para a educação profissional e tecnológica. Revista Brasileira da Educação Profissional e Tecnológica, Natal, v.I, n.I, p. 23-38, jun. 20o8. Disponível em: http://www2.ifrn.edu.br/ojs/index.php/RBEPT/article/view/2863. Acesso em: 09 jan. 202I.

SAVIANI, Demerval. Formação de professores: aspectos históricos e teóricos do problema no contexto brasileiro. Disponível em: http://www.scielo.br/pdf/rbedu/vi4n4o/vi4n4oai2.pdf

SAVIANI, Dermeval. Os saberes implicados na formação do educador. In: BICUDO, Maria Aparecida Viggiani; SILVA JUNIOR, Celestino Alves da (Orgs.). Formação do educador: dever doestado, tarefa da universidade. São Paulo: Unesp, 1996. p.I45-155.

SAVIANI, D. O choque teórico da politecnia. Revista trabalho, educação e saúde. Rio de Janeiro: Ed. Fiocruz, v. I, n. I, p. 131-52, 2003.

TANURI, L. M. História da formação de professores. Revista Brasileira de Educação. Rio de Janeiro, n. I4, p. 6i-193.

TARDIF, Maurice. Saberes docentes e formação profissional. Petrópolis: Vozes, 2008.

TIBALLI, E. F. A. Considerações pedagógicas a respeito da formação do professor reflexivo. Educativa, Goiânia, v. 4, n. 2, p. 241-250, jul./dez.20or. 